\title{
BENDING PROPERTIES OF A FUNCTIONALLY GRADED POLYMERIC COMPOSITE REINFORCED WITH A HYBRID NANOMATERIAL
}

\author{
Mahdi M. S. Shareef ${ }^{1}$ \\ Ahmed Naif Al-Khazraji ${ }^{1}$ \\ Samir Ali Amin ${ }^{1}$ \\ hjr.majeed@gmail.com \\ 20043@uotechnology.edu.iq \\ Samir.A.Amin@uotechnology.edu.iq
}

${ }^{1}$ Department of Mechanical Engineering, University of Technology - Iraq

\begin{abstract}
In this paper, functionally graded polymer hybrid nanocomposites have been produced by silica $\left(\mathrm{SiO}_{2}\right)$ nanoparticles and alumina $\left(\mathrm{Al}_{2} \mathrm{O}_{3}\right)$ nanoparticles distributed in a matrix of epoxy during the ultra-sonication via hand lay-up method. The variation in nanoparticles volume fraction (Vf.) has been given in the thickness direction for reaching the gradation. Each layer has a thickness of $1.2 \mathrm{~mm}$ through various concentrations of nanoparticles and is sequentially cast in acrylic moulds to fabricate the graded composite sheet with a $6 \mathrm{~mm}$ thickness. To fabricate the functionally graded layers, various concentrations of different nanoparticles $\left(1.5 \% \mathrm{SiO}_{2}, 1 \%\right.$ $\mathrm{SiO}_{2}$, epoxy, $2 \% \mathrm{Al}_{2} \mathrm{O}_{3}$ and $3 \% \mathrm{Al}_{2} \mathrm{O}_{3}$ ) have been used for tensile and compressive testing each isotropic layer of functionally graded material (FGM). The mechanical property that was studied for pure epoxy, isotropic and FGM was the flexural resistance. The flexural properties of FGM, isotropic nanocomposite $\left(1 \% \mathrm{SiO}_{2}+2 \% \mathrm{Al}_{2} \mathrm{O}_{3}\right)$ and pristine epoxy, for evaluating their mechanical properties, including flexural stress-strain criteria and flexural Young's modulus, were determined via a Three-point bending test, with loading from the side of silica and alumina for the hybrid-FGM and at one side for the isotropic hybrid nanocomposite and pristine epoxy. The mechanical properties (tensile and compression) and the density of every layer were obtained for the epoxy resin and nanocomposites. They can benefit from the Finite Element Analysis (FEA) of the Three-point bending test via the Design Modeler (ANSYS workbench). The results of experiments were confirmed via building a detailed 3D FE model. Also, the advanced deformation results from the FE model were found in good agreement with the experimental outcomes.
\end{abstract}

Keywords: Polymer nanocomposites, FGM, Tensile properties, Compression properties, Flexural properties

\section{خصائص الانحناء لمركب بوليمر متارج وظيفيًا معزز بمادة نانوية هجينة}

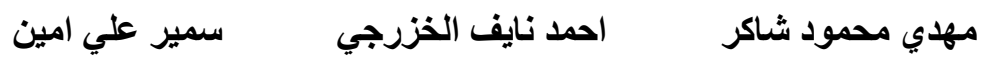

في هذا البحث، تم إنتاج المركبات النانوية الهجينة البوليمرية المتدرجة وظيفيًا بواسطة جزيئات السيليكا (Al

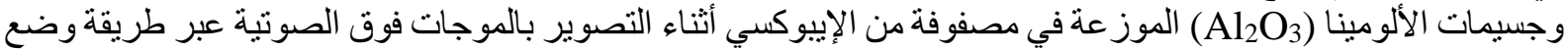

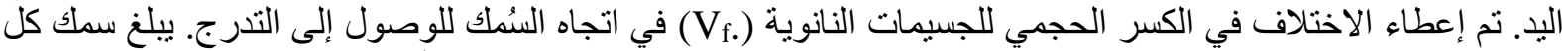

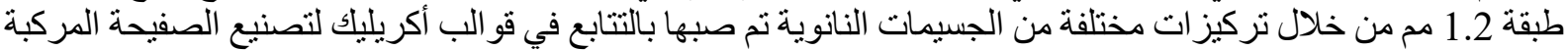

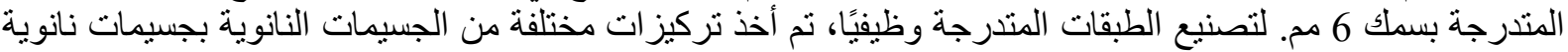

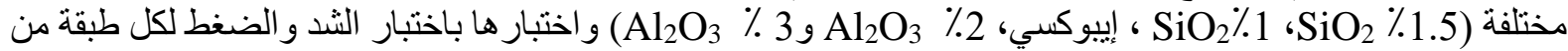




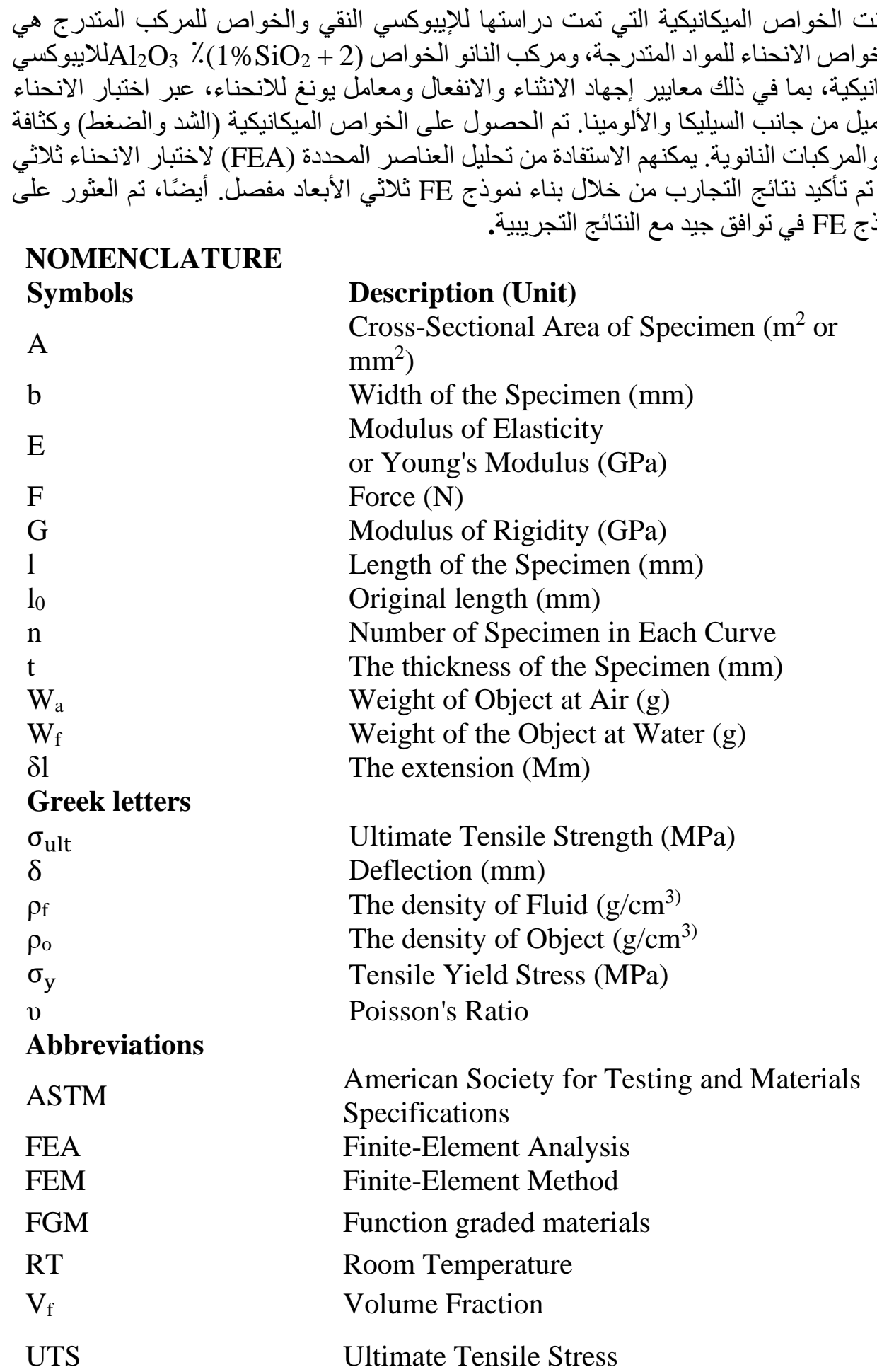

\section{INTRODUCTION}

FGM belongs to a group of composites prepared via utilizing a specific method evolved to attain properties that cannot be performed via monolithic materials. It can be described via the gradual change in composition and structure over a volume. The results are the consistent variations in the material properties, such as the modulus of elasticity, hardness, resistance to wear or bio-compatibility. The functionally graded material concept was initially suggested in (80's) for developing the heat-resistant materials for the propulsion system and the airframe of 
space planes. Certain areas of action, such as biomedical or aeronautical manufacture, are concerned by FGM developments (Mehditabar et al., 2019). FGMs are composites, where the composition differs from position to position to affect the best structure performance. The evolution of the functionally graded material has revealed its potential applications in a broad range of structural and thermal uses, like the coatings of thermal barriers and the coatings that resist wear and corrosion. The gradation of mechanical properties provides the methods of optimizing the structure and performing a high performance and material efficiency. Simultaneously, such optimization can cause many mechanical difficulties, comprising the effective properties valuation and crack propagation behavior in the last structure (Saleh et al. (2020) and Parihar et al. 2017). Brijesh et al. (2019), prepared graded and homogenous glass fiber and marble dust strengthened vinyl-ester composite materials and investigated their effect on the mechanical properties and resistance to wear performance. Regarding the mechanical properties, the tensile and hardness properties of the two graded and homogenous composite materials showed rising tendencies; furthermore, the graded composites revealed a preeminence impact over the homogenous composite materials. In contrast, the toughness of the graded and homogeneous composite materials specimens decreased with an increment in the weight percentage of marble dust. Singh and Vashishtha (2016), studied the behavior of the nano titanium dioxide $\left(\mathrm{TiO}_{2}\right)$ filler-increased nanocomposites with the mechanical properties and the resistance to wear. Correspondingly, the nano $\mathrm{TiO}_{2}$ (titanium dioxide)-filler, polyester-based homogeneous nanocomposites and functionally graded materials were produced via mechanical stirring and vertical centrifugal casting. Nevertheless, the specimens were restricted to a cylindrical shape due to the centrifugation working principle, and merely one distinctive gradient pattern can be determined. Mishra et al. (2020), established a novel technique to fabricate a layered functionally graded polymer nanocomposite (FGPNC) of the epoxy and alumina nanoparticles $\left(\mathrm{Al}_{2} \mathrm{O}_{3}\right)$. The influence of the gradation and shape of the particles of $\mathrm{Al}_{2} \mathrm{O}_{3}$ upon the flexural properties of FGPNC was investigated. Also, nanocomposite monolithic specimens of epoxy and $\mathrm{Al}_{2} \mathrm{O}_{3}$ nanoparticles were utilized as the functionally graded polymer nanocomposite layers were prepared. Tensile properties of the nanocomposites' monolithic models were used to analyze the outputs determined for the FGPNC. Abbas and Raheem (2019), prepared functionally graded polymer nanocomposites (FGPNCs) by hand layup technique by adding graphene and carbon nanotubes particles with different weight fractions (1 and $3 \mathrm{wt} . \%$ ) to epoxy. The FGPNC flexural properties for each weight fraction were found via a Three-point bending test, with loading from the side of neat epoxy and composite. The results displayed that Young's modulus and flexural strength with loading from the side of neat epoxy were more significant than those for the specimens loaded from the side of composites. Ahmed et al. (2018), used a numerical study by using ANSYS. Experimental methods to investigate the flexural and impact behavior of the functionally graded rubber strengthened by various ratios of Wollastonite as a core in the sandwich composite and the epoxy resin reinforced by carbon fibers, which act as a skin in the structure of the sandwich composite.

Abbas and Raheem (2019), made functionally graded polymer nanocomposites via the hand lay-up method by adding graphene and carbon nanotubes with different weight fractions ( 1 and $3 \mathrm{wt} . \%)$ to epoxy resin. The hardness and impact strength of functionally graded polymer nanocomposite for each weight fraction was determined for the pure and composites side. The results elucidated that the hardness and impact strength loaded from the composite side are higher than those for the specimens loaded from the side of pure epoxy and are generally observed higher for the carbon nanotubes composites than graphene composites. Akant and Sanjay (2020), investigated the effect of nano Titanium Oxide $\left(\mathrm{TiO}_{2}\right)$ filler and the synthesis method upon the mechanical properties of the filler filled vinyl ester composites. $\mathrm{TiO}_{2}$ filled vinyl ester-based Homogeneous Nano Composites (HNCs) and their FGMs were synthesized 
utilizing stirring as well as the method of centrifugal casting, correspondingly. Homogeneous nanocomposites and functionally graded materials were produced with the reinforcement of (5 $\mathrm{wt} \%)$ and $(10 \mathrm{wt} \%)$ of nano $\mathrm{TiO}_{2}$ fillers, correspondingly. Also, the neat vinyl ester was synthesized for the compression performance with the homogeneous nanocomposites and functionally graded materials. The obtained outcomes revealed that the nano $\mathrm{TiO}_{2}$ filled functionally graded materials performed better than the homogeneous nanocomposites. İrez and Bayraktar (2020), studied the influence of silica reinforcement (5-10-15 wt.\%) and the different contents of Graphene Nanoplatelets (GnPs) and particles of alumina upon the toughness. In such concern, notched samples were utilized to determine the Critical Stress Intensity Factor and the rate of the Critical Strain Energy Release. The fracture toughness depicted certain variations via the incremental amount of reinforcements. Furthermore, the flexural strength and the modulus of elasticity were computed by 3-point bending tests. Shareef et al. (2021), made Layered-Functionally Graded Polymer Nanocomposites (FGPNCs) via the nanoparticles of silica $\left(\mathrm{SiO}_{2}\right)$ distributed into the matrix of epoxy using the ultra-sonication via hand lay-up method. For fabricating the FG layers, various concentrations $(0,0.5,1,1.5,2$, and $2.5 \% \mathrm{Vf})$ of nanoparticles were used and examined via tensile test. The flexural properties of three functionally graded materials were determined via a three-point bend test to evaluate their mechanical properties. Results elucidated that the modulus of elasticity and flexural strength loaded from the side of pure epoxy were higher than those for specimens loaded from the side of composites for the (FGM1). Shareef et al. (2021), prepared Functionally Graded Polymer Nanocomposites (FGPNCs) via mixing the alumina $\left(\mathrm{Al}_{2} \mathrm{O}_{3}\right)$ nanoparticles with an epoxy matrix through five layers of $(1.2 \mathrm{~mm})$ thickness for each layer using hand lay-up technique. Different volume fractions $(0,1,2,3$ and $4 \%)$ were taken of the used nanoparticles. Tensile and compressive tests tested the prepared isotropic Specimen. The results showed that the (4\% Vf of $\mathrm{Al}_{2} \mathrm{O}_{3}$ ) enhanced the ultimate tensile strength (85.25\% from neat epoxy) and decreased after that. The flexural modulus and the flexural strength of the FGPNC for each type of FGMs enhanced by (67\%) and (51.7\%), respectively for (FGM1) loaded from the side of pure epoxy. According to the literature stated above, it's evident that many studies have been performed on polymer-based FGMs. Still, to the excellent knowledge of authors, the nano $\mathrm{SiO}_{2}, \mathrm{Al}_{2} \mathrm{O}_{3}$-filled epoxy-based FGMs haven't been synthesized up to now, and the proper gradation of bending property for each layer was not perversely conceded. The present investigation aims to conduct a novel synthesis method to produce stepwise graded and non-graded hybrid nanocomposites laminates with three materials (epoxy, nano-silica and nano alumina) and hand lay-up procedure. The functionally graded hybrid nanocomposite was used and compared to the epoxy and the isotropic composite materials. The experimental test was compared to the FE model and elucidated a virtuous covenant with the flexural test.

\section{NANOCOMPOSITE PREPARATION AND FINITE ELEMENT MODELLING Utilized material}

The epoxy resin with a trademark (Quickmast 105 base) was used in a liquid form as a matrix with lower viscosity than the other thermosets. It was then converted into a solid-state by adding a hardener (Quickmast 105 hardener) using the manufacturing company's ratio of (4:1.47). The (Quickmast 105) technical characteristics are listed in Table (1), relying upon the datasheet of (DCP) company. In contrast, the nanoparticle reinforcements being silica produced via "Guangzhou Billion Peak Chemical Technology Co. Ltd" with the characteristics given in Table (2). In contrast, the nanoparticle reinforcements are alumina manufactured by Briture Company Ltd., with the characteristics shown in Table (3). Inorganic reinforcements, alumina $\left(\mathrm{Al}_{2} \mathrm{O}_{3}\right)$ has decent mechanical properties, thermal stability, and good wettability properties with epoxy resin. Besides, it is non-toxic and inexpensive (İrez and Bayraktar (2020). The $\mathrm{A}_{1}$ 
oxide has been utilized as a filler due to its elevated hardness; in the nanometric sizes, alumina verifies its high hardness and thus its capability to enhance the nanocomposites' mechanical properties. $\mathrm{Al}_{2} \mathrm{O}_{3}$ is widely obtainable in the market in multiple purities and particle sizes at a reasonable price (Noor and Mohammed 2019). Silicon dioxide, alternatively referred to as silica (from Latin Silex), is a chemical compound having a chemical formula $\left(\mathrm{SiO}_{2}\right)$, which is one of the most complex and abundant material families, occurring naturally in various minerals and synthesized synthetically (Li et al., 2015). Due to its high strength, fracture toughness, wear resistance, and high specific surface area, $\mathrm{SiO}_{2}$ nanoparticles are frequently used as nanofiller to prepare polymer nanocomposite materials (Franco, 2017).

\section{Preparation of Nanocomposites}

Acrylic molds possessing a thickness of $(6 \mathrm{~mm})$ were cut via CNC laser apparatus. Nanocomposites were fabricated via the hand lay-up method. In this work, (2) types of nanoparticles (alumina and silica) were chosen as nano-fillers; also, the epoxy in the form of liquid was utilized as a matrix. The entire addition procedure of reinforcement to resin was done in a suitable thinner solvent to prepare a uniform mix. For the neat epoxy samples preparation for producing identical states compared to the other samples, a proper amount of epoxy was placed into a sufficient quantity of solvent. Beyond ( $15 \mathrm{~min}$ ) of blending employing a magnetic stirrer, the mix was placed in a beaker for putting it into a vacuum container; this solvent must also be entirely evaporated under a vacuum condition made via a vacuum pump. Within this stage, the stoichiometry ratio of the hardener, that means (4 epoxy:1.47 hardener), was added and mixed uniformly for a period of (15 $\mathrm{min})$ as well as degassed by a vacuum pump to remove the air's bubbles, as depicted in Figure (1). Such mix was placed in a mold for two days curing at room temperature (RT). For the isotropic epoxy/nano-particles preparation, the preferred reinforcements quantities $(0.5,1,1.5$, and $2 \mathrm{Vol} . \%)$ of $\mathrm{SiO}_{2}$ and for $\mathrm{Al}_{2} \mathrm{O}_{3}$ nanoparticles $(1,2$, 3 , and 4 Vol.\%) being melted into a suitable amount of specified solvent for a period of (15 min) in addition to isotropic hybrid $\left(1 \% \mathrm{SiO}_{2}+2 \% \mathrm{Al}_{2} \mathrm{O}_{3}\right)$. The resulted mix was completed consistently by a magnetic stirrer for a period of $(15 \mathrm{~min})$ as well as sonicated at $(75 \%)$ amplitude for $(15 \mathrm{~min})$; $(50 \mathrm{sec}$. On) and (10 sec. Off). The required epoxy amount was supplemented to such mix via the same method as specified previously and blended mechanically. The hardener's stoichiometry ratio was augmented to a mixture, stirred mechanically, and degassed by a vacuum pump to remove the air's bubbles. Lastly, the consistent mix was put into molds for curing for two days. A square mold ( $225 \mathrm{~mm} \times 225 \mathrm{~mm} \times 6$ $\mathrm{mm}$ ) was utilized; a CNC machine was also used to cut the resulting square for specimen preparation. The used mold is displayed in Figure (2).

\section{Functionally Graded Polymer Nanocomposite (FGNC) Preparation}

The synthesis procedure of FGNCs was separated into two various steps; Preparation of the mix of nanofiller and melted matrix via a proper dispersal and blending techniques as in the abovementioned process for the isotropic nanocomposite, and a successive casting of the melted mixture into layered molds relying on a pre-designed graded structure. These layers possessed a $(1.2 \mathrm{~mm})$ thickness released into the acrylic molds. To fabricate a hybrid-FGM, the preliminary required amount of mix for the $\left(3 \% \mathrm{Vol}\right.$.) of $\mathrm{Al}_{2} \mathrm{O}_{3}$ was first gently poured into the mold's cavity possessing a $(1.2 \mathrm{~mm})$ thickness and after that cured for $(1 \mathrm{hr})$. Then, the $2 \mathrm{nd}$ layer of nanocomposites having $\left(2 \% \mathrm{Al}_{2} \mathrm{O}_{3}\right)$ nanoparticles was cast on the previously released semi-cured layer. Later, the hybrid-FGM was allowed to be cured for (1 hr). Similarly, further nanocomposites layers of (epoxy, $1 \% \mathrm{SiO}_{2}$ and $1.5 \% \mathrm{SiO}_{2}$ ) of nanoparticles were cast one after another to fabricate the FGNC sheet possessing a $(6 \mathrm{~mm})$ thickness as well as the similar process for the else samples of functionally graded materials manifested in Figure (3). The other models were fabricated in the same procedure. 


\section{Finite Element Modelling}

Daily in the technology field of composite, novel materials are being evolved, or the materials are being designed utilizing various nanomaterials to enhance the characteristics of the hybrid composite. The consumption period is costly for testing the whole novel materials designed and synthesized using the nanomaterials. Therefore, there's a requisite for an influential tool for analyzing the characteristics of the nanoengineered composite employing analytical approaches. The nanocomposites failure can give a vision for the nanomaterials influences upon the attributes of the nanoengineered composite. FEM is justly precise and is the highly sophisticated modelling of intricate 3D composites. This investigation introduces the detail of 3D FE modelling and the analysis for simulating the advanced failures in composites for a 3Point Bend test for studying the nanoparticles influences upon the composite beams. Models being evolved employing the ANSYS FE software. The FG nanocomposites' flexural modulus was assessed using the (ANSYS) Multiphasic Code (Version 2020 R2). The friction between the Specimen and the jigs wasn't considered in this study. The FG nanocomposites' layers were considered as one homogenous isotropic elastic material. The FE model of flexural tests was conducted, as elucidated in Figure (4). The nodes are (50892) (jigs: 16652 and Specimen: 34240). In this model, the Cartesian coordinate system was utilized with the (X), (Y) and (Z) axes in the directions of length, width, and thickness, correspondingly. 8-node solid 186 elements were employed for meshing the specimens. The contact elements were utilized for the contact region between the test fixture and the Specimen. The coefficient of friction for the contacting surfaces was presumed to become without conflict. The sample was burdened via a given displacement $\left(\delta_{\mathrm{o}}\right)$ on the top-loading nose surface in the $(Z)$ direction. The calculated load $\left(\mathrm{P}_{\mathrm{o}}\right)$ corresponds to the load measured by a load-cell through the experimentations.

Poisson's ratio for every layer described at different nanocomposite volume fractions from the Mixture rule is provided as an input to the finite element analysis, as depicted in Table (4). The FGM's modulus elasticity and the density defined at different nanocomposite volume fractions from the experimentations (Tensile test) implementing the principle of Archimedes were given as input to the FEA.

\section{EXPERIMENTAL PART \\ Density}

The theoretical density $\left(\rho_{\mathrm{th}}\right)$ of the composite was calculated employing the rule of mixture (ROM), using the following expression (Mishra et al., 2020):

$\rho_{\text {th }}=V_{p} \rho_{p}+V_{e} \rho_{e}$

Where:

$\left(\rho_{e}\right),\left(\rho_{\mathrm{p}}\right)\left(\mathrm{V}_{\mathrm{e}}\right)$, and $\left(\mathrm{V}_{\mathrm{p}}\right)$ are the density and volume fraction of the epoxy matrix and nanoparticles, correspondingly.

The samples' density of the epoxy and the FGPNC was obtained experimentally using Archimedes' principle. The density of composites was calculated utilizing the following formulas (Mishra et al.,2020):

$\rho_{c}=\frac{W_{a}}{\left(W_{a}+W_{w}\right)}$

Where:

$\rho_{c}$ : The density of composite.

$\mathrm{W}_{\mathrm{w}}$ and $\mathrm{W}_{\mathrm{a}}$ : The sample's weights in water and air, correspondingly.

\section{Tensile and compressive test}

The tensile and compressive properties of the nanocomposite samples at various volume fractions being determined by the standards ASTM D638 (2015) and ASTM D 695 (2015), respectively, as shown in Figure (5) and Figure (6), using (50 kN) Servo Hydraulic Computerized Universal Testing Machine (Tinius Olsen H50KT tensile testing machine), as 
shown in Figure (7). These tests were conducted at a cross-head speed of $(1 \mathrm{~mm} / \mathrm{min})$. The mean modulus of elasticity and strength were calculated by performing at least five valid tests. The test samples' tensile and compressive stresses were computed utilizing this formula (Ferdinand et al., 2015):

$\sigma=\mathrm{P} / \mathrm{A}$

Where:

$\sigma:$ Stress

P: The exerted load

A: Cross-sectional area perpendicular to the exerted load direction

The samples' modulus of elasticity was computed via dividing the tensile or compressive stress upon the strain in the linear portion of the stress-strain curve between the strain $(0.05 \%)$ and $(0.25 \%)$, utilizing the equation below (Ferdinand et al., 2015):

$E=\frac{\sigma_{2}-\sigma_{1}}{\varepsilon_{2}-\varepsilon_{1}}$

Where $\varepsilon_{1}$ is the 0.0005 strain, $\varepsilon_{2}$ is the 0.0025 strain, $\sigma_{1}$ is the stress at $\varepsilon_{1}$, and $\sigma_{2}$ is the stress at $\varepsilon_{2}$.

\section{Flexural Test}

In the samples of the FGPNC, the gradation is delivered in the thickness direction, meaning that the stiffness property varies in the thickness direction. Flexural properties of neat epoxy, $2 \%$ Vf. alumina nanocomposite and FGMs were determined by implementing a Three-point bending test. The samples were loaded from the epoxy and nanocomposite sides on the tensile testing device (FGM1) and one side for the other models. The sample's sizes of the flexural test are $60 \mathrm{~mm}$ in length (L), $10 \mathrm{~mm}$ in Width (W), and $6 \mathrm{~mm}$ in Thickness (B), correspondingly as displayed in Figure (8) by the standard ASTM D790 (2015). The flexural strength modulus and were calculated via these expressions:

$\sigma_{f}=\frac{3 P L}{2 W B^{2}}$

$\varepsilon_{f}=\frac{6 D B}{L^{2}}$

$E_{b}=\frac{m L^{3}}{4 W B^{3}}$

Where:

$\sigma_{f}$. Flexural stress

$\varepsilon_{f}$ : Flexural strain

$E_{b}$ : Flexural modulus

P: Maximum load

D: Deflection

M: The tangent slope to the 1st linear region of the Load - Deflection curve

At a minimum, five samples were tested for each kind of sample. In the present investigation, the support's roller diameters and the loading nose were $(10 \mathrm{~mm})$, respectively.

\section{RESULTS AND DISCUSSION \\ Density and void content results}

Incorporating fillers into the matrix or throughout the manufactures of nanocomposites, either the volatiles or the air might be caught in composite materials, and they will be as micro voids, which might considerably influence some of their mechanical properties. The void quantity in the nanocomposite materials can be accessed by comparing their actual density with their theoretical density. The influence of the $\left(\mathrm{V}_{\mathrm{f}} \%\right)$ of the alumina and silica nanoparticles $\left(\mathrm{V}_{\mathrm{f}} \%\right)$ upon the investigational density of epoxy composites increased the density of the matrix material of epoxy, as revealed in Table (5), approving the nanofillers advantage as a particulate strengthening. It's clear from this Table that the experimental density and the percentage of 
epoxy void increase with the incorporation of nanoparticles. Also, from this Table, it can be seen clearly that the FGPC of the two particles possesses has a lower density than their pertinent monolithic nanocomposites treating silica nanoparticles (1Vf. \%) and alumina nanoparticles (2Vf.\%). Therefore, one can state that for a specific sample size, the gradation in the particles volume fraction (Vf. \%) can lower the weight of FGPC compared to that for the monolithic nanocomposites.

\section{Tensile and compression test results}

The volume fractions of the nanomaterials were determined by making more than one volume fraction ranging from $(0 \%$ to $5 \%)$, and the best values were taken by examining the tensile strength and the complement shown by the two references Shareef et al. (2021).

Figure (9) and Figure (10) display the stress-strain curve of the pure epoxy and the epoxy with various nanoparticles $\left(\mathrm{SiO}_{2}\right.$ and $\left.\mathrm{Al}_{2} \mathrm{O}_{3}\right)$ at different volume fractions under the tensile and compressive load, respectively. Adding stiff particles to a polymer matrix can improve its stiffness because the rigidity of inorganic fillers is generally higher than that of the organic polymers. The modulus of elasticity is enhanced via the addition of nanoparticles to the polymer matrix. The nanoparticles provide increased rigidity to polymers Bhattacharya (2016). The initial linear region's slope of the curve is employed to obtain the modulus of the elasticity of Specimen. The increased non-linearity in the stress-strain turn indicates a larger plastic region. The lower slope reveals the low stiffness of the composites. The tensile and compressive strengths of pure epoxy and epoxy with different nanocomposites were calculated using the maximum load ratio obtained by Specimen and the original cross-sectional area inside Specimen's gauge region. As observed from the compressive strength values shown in Figure 10, they're higher than the tensile strength value displayed in Figure (12). The brittle materials like the polymer composite are realized via the truth that their compressive strength value is more than their value of tensile strength. Figures 11 and 12 were drawn for epoxy with different nanocomposites and volume fractions for tensile and compression, respectively. Results illustrated that both nanoparticles are influential for enhancing the modulus of elasticity and the maximum strength compared with the epoxy resin for tensile and compressive tests. At the $(1.5 \% \mathrm{Vf}$.) of the nanoparticles of silica, the rise from $0.615 \mathrm{GPa}$ to $0.77 \mathrm{GPa}$ (i.e. increased by $25.2 \%$ ) in the elastic modulus and the UTS increase from $27.8 \mathrm{MPa}$ to $47.9 \mathrm{MPa}$ (i.e. increased by $72.3 \%$ ) were found higher than those for the neat epoxy. Also, for (3\% Vf) of alumina nanoparticles, the enhancement from $0.615 \mathrm{GPa}$ to $0.804 \mathrm{GPa}$ (with the percentage of $30.7 \%$ ) in the modulus of elasticity and from $27.8 \mathrm{MPa}$ to $45.12 \mathrm{MPa}$ (with the rate of 62.3\%) in the maximum tensile strength was more than those of pure epoxy. The compressive strength values for $(1.5 \% \mathrm{Vf})$ of silica increased from $48.7 \mathrm{MPa}$ to $63.38 \mathrm{MPa}$ (i.e. by $31 \%$ ). And the modulus of elasticity increased from $(0.813 \mathrm{GPa})$ to $(1.144 \mathrm{GPa})$ by (i.e., by $40.7 \%)$ from the pristine epoxy. Also, for (3\% Vf) of alumina nanoparticles, the increase from $48.7 \mathrm{MPa}$ to $63.38 \mathrm{MPa}$ (increased by $30 \%$ ) in the ultimate compressive strength and from $0.813 \mathrm{GPa}$ to $1.056 \mathrm{GPa}$ (increased by $30 \%$ ) in the modulus of elasticity was higher than those for pure epoxy. Figures (10) and (11) demonstrate that mixing $1 \%$ vol. silica nanoparticles with $2 \%$ vol. alumina nanoparticles give the modulus of elasticity and the ultimate tensile strength less than before mixing each other and remain higher than the neat epoxy for both tensile and compressive test results. This shows the higher tensile toughness in comparison with pure epoxy. The increased tensile strength of nanocomposite results from the increased interfacial interaction between the matrix and the nanoparticles, which improves stress transfer in the composites. Due to the interface between the matrix and the nanoparticles (imperfect bonding), the stress concentration and void content effects may reduce the UTS below the threshold value. Thus, the interfacial debonding between the matrix and the nanoparticles must be considered during the modelling process. The most critical parameter affecting the strength of the two-phase composite is the 
working stress transfer. Stress transfer at the particle/polymer interface is ineffective for the weakly bonded particles. The intermittent debonding occurs due to the particle's non-adherence to the polymer. As a result, the particle cannot carry every load, and the composite's strength decreases as the particle loading increases. However, for the composites that contain wellbonded particles, adding particles to the polymer will increase the strength, particularly for nanoparticles with large surface areas (Jeevanandam et al.,2018). Those agglomerates become impurities and result in the origin of the failure. When the concentration increases, the number of particles increases, resulting in particle-particle interactions rather than particle-matrix interactions. As a result, these particles aggregate and form lumps, affecting the Van der Waals interaction between the polymer chains and potentially reducing strength characteristics (Uygunoglu et al., 2015). The modulus of elasticity computed for each layer from tension and compression tests was utilized into the FEA for comparing the flexural characteristics from the experimental work.

\section{Results of flexural test}

Stress-strain curves determined from the Three-point bend tests of the neat epoxy specimens (layered) and the isotropic nanocomposites (layered) as well as the functionally graded materials are displayed in Figure (13) - failure of FGPN in the flexural mode being governed by the crack spread. The fracture of all specimens took place because of the crack spread from the tensile side to the compression. It was observed that the samples fractured from the middle; also, delamination didn't occur, indicating the suitable bonding among the layers. A comparison of flexural strength and the modulus of elasticity for pure epoxy, isotropic, and functionally graded materials is illustrated in Figure (14). The results exhibited that the increase from 81.35 $\mathrm{MPa}$ to $103.35 \mathrm{MPa}$ (i.e. $27.2 \%$ enhancement) in flexural strength and from $1.95 \mathrm{GPa}$ to 2.65 GPa (i.e., 36\% improvement) in the flexural modulus of the FGPN loaded from the alumina side was higher than those of the layered pure epoxy specimens. At the same time, the enhancement from 81.35 MPA to 103.35 MPa (21.5\%) in flexural strength and from 1.95 GPa to $2.8 \mathrm{GPa}(43.5 \%)$ in flexural modulus was more than those of the layered epoxy specimens if loaded from the silica side. But, in the case of the hybrid isotropic $\left(1 \% \mathrm{SiO}_{2}+2 \% \mathrm{Al}_{2} \mathrm{O}_{3}\right)$, a slight enhancement was observed in both flexural strength and modulus compared with the hybrid functionally graded nanocomposite loaded from the silica and alumina side. Compressive stress is applied to the layers where the load is exerted, while the tensile stress is used on the opposite side during the flexural test. In contrast, the layers beneath the neutral axis will experience tensile stresses during the Three-point bend test. By contrast, the layers above the neutral axis (i.e., to the loading side) will share the compressive stresses via the modulus of elasticity and the nanocomposites single layer density, with the neutral axis of the layered FGPN being determined to be approximately at the thickness direction's middle plane. Thus, the gradation did not significantly shift the neutral axis away from the centroid axis, owing to the highly variable density of nanocomposites at various nanoparticle concentrations.

The spread of crack initiated in a layer at tensile stress will become more accessible than the layer at compressive stress. So, the three-point bend test's stiffer and robust layers in the tensile stress region greatly enhance the FGPN flexural features. Therefore, for the 3-Point Bending Test, the most exterior layer (layer opposite to the applied load surface) plays an essential part in the flexural features increment of FGPNC. The layered FGPNC with a robust and stiffer exterior layer will have well flexural feature. The results determined from the ANSYS software are manifested in Figure (14). The same loads were implemented to those exerted in the actual state, comparing the resulting deflection and the actual deflection. The experimental work included computing the density, Poison's ratio, and modulus of elasticity for every layer. A virtuous agreement was found between the finite element analysis and the experimental work, 
with a maximum error of $3.17 \%$ at FGM-hybrid samples due to the void content in these specimens.

\section{CONCLUSIONS}

The following conclusions can be drawn depending on the results of the present study:

1. The mixed silica and alumina nanoparticles reinforcing with a gradation within the layered shape can be a remarkably attractive process to improve the flexural features of the FGPNC over those of the isotropic nanocomposite with a maximum flexural stress enhancement of $(14.8 \%)$.

2. The flexural strength of the sample loaded from the alumina side was higher than that for the model loaded from the silica side $(4.6 \%)$. And, Young's modulus of the sample loaded from the silica side was higher than that for the sample loaded from the alumina side for FGM by $(5.6 \%)$.

3. Flexural strength and flexural modulus for the hybrid-FGM loaded from the side of alumina or silica were higher than those for the samples loaded for the isotropic hybrid nanocomposite $\left(1 \% \mathrm{SiO}_{2}+2 \% \mathrm{Al}_{2} \mathrm{O}_{3}\right)$ by $(14.4 \%$ for the alumina rich side), (9.7\% for silicarich side) for flexural strength and by ( $7.8 \%$ for the alumina rich side) and (14.3\% for silicarich side) for Young's modulus

4. A good agreement was found between the results of conducted experiments and FEA employing the ANSYS program for the flexural analysis. The delamination between the layers of the samples of FGMs did not occur, and the FGM's models were not present well built. The maximum discrepancy was $(3.1 \%)$ for Young's modulus when the models of the hybrid-FGM were loaded from the silica side.

Table 1. Properties of the Quick mast 105 (Manufacturer datasheet )

\begin{tabular}{|l|l|}
\hline Properties & Values \\
\hline Compressive strength $(\mathrm{MPa})$ & 50 \\
\hline Flexural strength $(\mathrm{MPa})$ & 82 \\
\hline Tensile strength $(\mathrm{MPa})$ & 28 \\
\hline Density $\left(\mathrm{g} / \mathrm{cm}^{3}\right)$ & 1.15 \\
\hline Viscosity (poise) & $3-5$ at $25^{\circ} \mathrm{C}$ \\
\hline Poisson's Ratio & $1-2$ at $35^{\circ} \mathrm{C}$ \\
\hline
\end{tabular}

Table 2. The nano silica $\left(\mathrm{SiO}_{2}\right)$ properties. (Manufacturer datasheet)

\begin{tabular}{|l|l|}
\hline Properties & Values \\
\hline Purity, \% & 99.5 \\
\hline Average Particle Size, $\mathrm{nm}$ & $14-36$ \\
\hline Specific Surface Area, $\mathrm{m}^{2} / \mathrm{g}$ & $580 \pm 20$ \\
\hline Microstructure Shape & spherical \\
\hline Poisson's Ratio & 0.18 \\
\hline Young's Modulus, GPa & 70 \\
\hline
\end{tabular}


Table 3. Properties of the nano Alumina $\left(\mathrm{Al}_{2} \mathrm{O}_{3}\right)$ (Manufacturer datasheet)

\begin{tabular}{|l|l|}
\hline Properties & Values \\
\hline Purity (\%) & 99.9 \\
\hline Average Particle Size, $\mathrm{nm}$ & $50-100$ \\
\hline Specific Surface Area, $\mathrm{m}^{2} / \mathrm{g}$ & $5-10$ \\
\hline Microstructure Shape & spherical \\
\hline Poisson's Ratio & 0.22 \\
\hline Young's Modulus, $\mathrm{GPa}$ & 347 \\
\hline
\end{tabular}

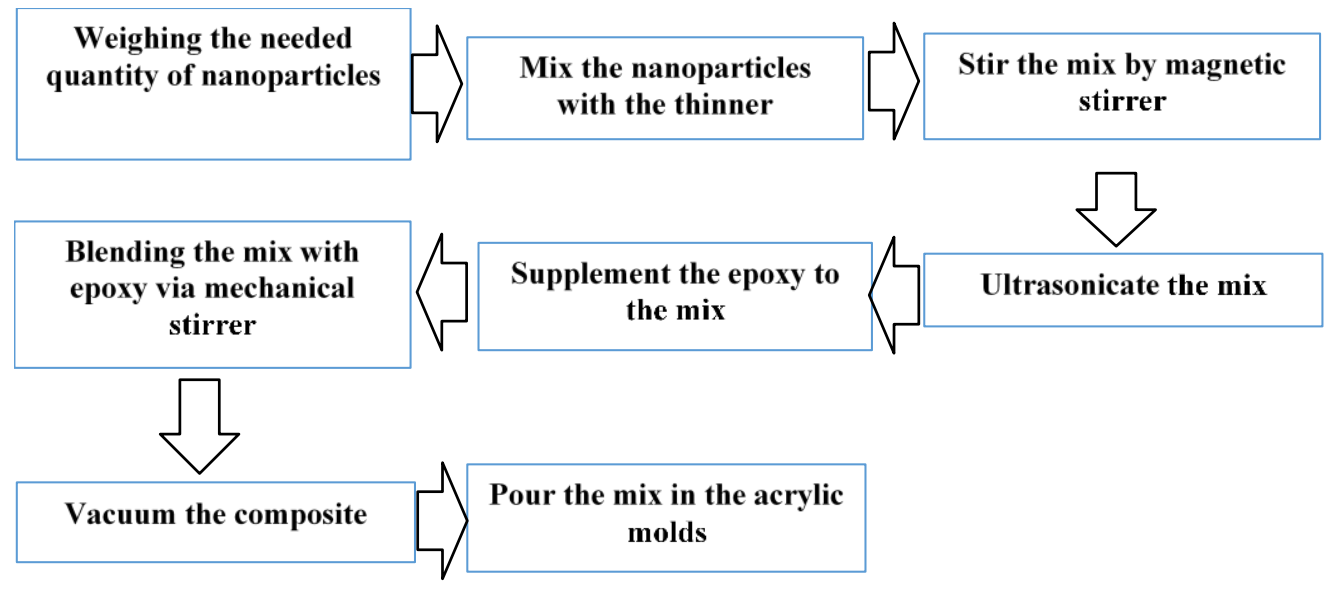

Fig.1. The procedure of the investigational work used for fabricating the consistent composite and the FG nanocomposite

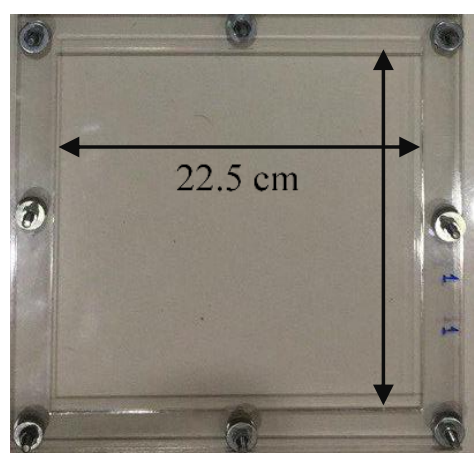

Fig.2. Composite and functionally graded materials mold

$1.5 \%$ Vf. $\mathrm{SiO}_{2}$
$1 \%$ Vf. $\mathrm{SiO}_{2}$
Pure epoxy
$2 \%$ Vf. $\mathrm{Al}_{2} \mathrm{O}_{3}$
$3 \%$ Vf. $\mathrm{Al}_{2} \mathrm{O}_{3}$

Fig.3. Hybrid functionally graded material sample (FGHNC) with different regions for hardness measurement 
Table 4. Poisson's ratio for every FGM layer

\begin{tabular}{|c|c|}
\hline Samples & $\begin{array}{c}\text { Poisson's ratio (Mixture } \\
\text { rule) }\end{array}$ \\
\hline Epoxy & 0.33 \\
\hline $1 \% \mathrm{SiO}_{2}$ & 0.3285 \\
\hline $1.5 \% \mathrm{SiO}_{2}$ & 0.32775 \\
\hline $2 \% \mathrm{Al}_{2} \mathrm{O}_{3}$ & 0.327 \\
\hline $3 \% \mathrm{Al}_{2} \mathrm{O}_{3}$ & 0.3255 \\
\hline $\mathrm{Hybrid}_{2}\left(1 \% \mathrm{SiO}_{2}+2 \%\right.$ & 0.32775 \\
\hline $\left.\mathrm{Al}_{2} \mathrm{O}_{3}\right)$ & \\
\hline
\end{tabular}

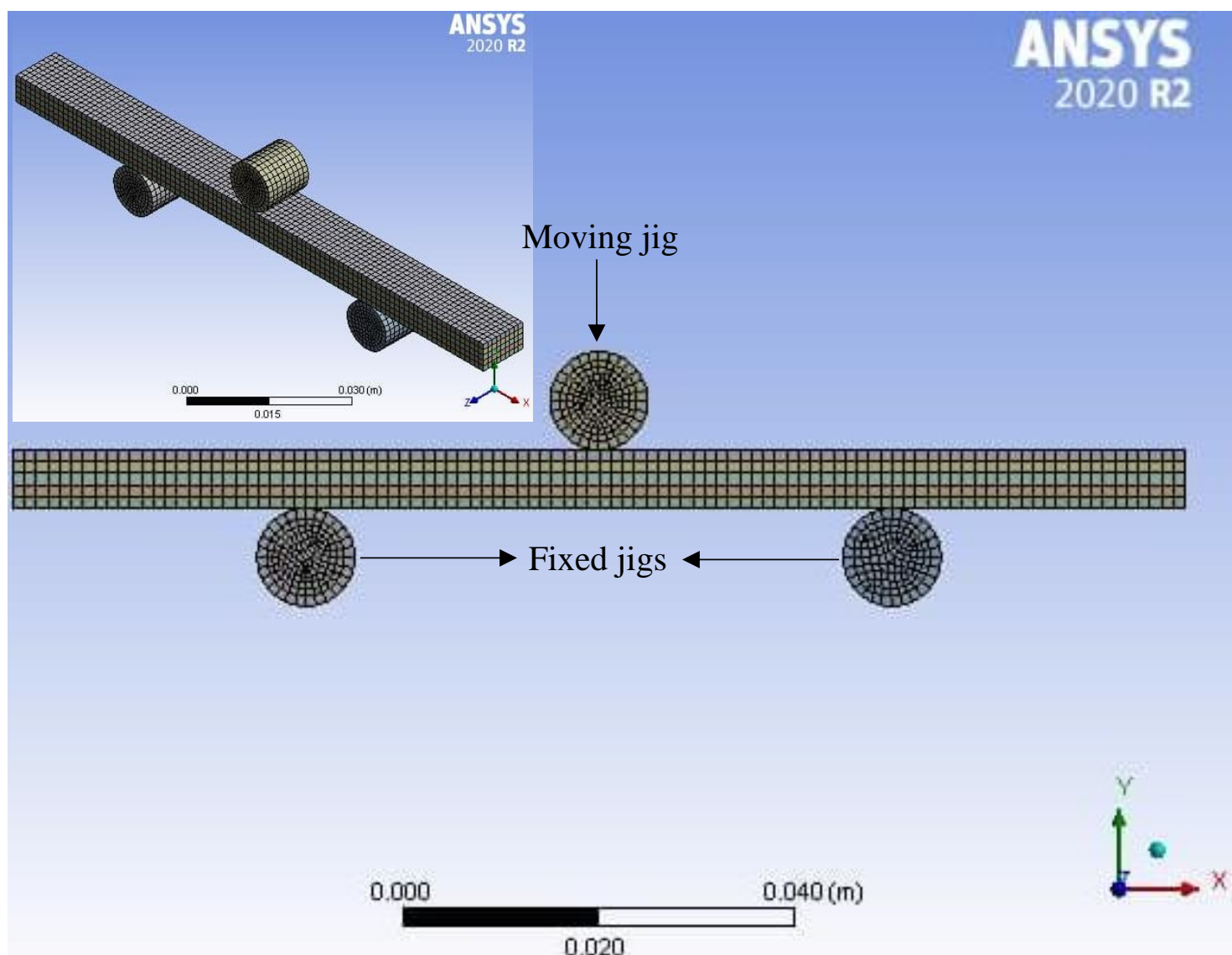

Fig.4 Finite element model for the flexural test

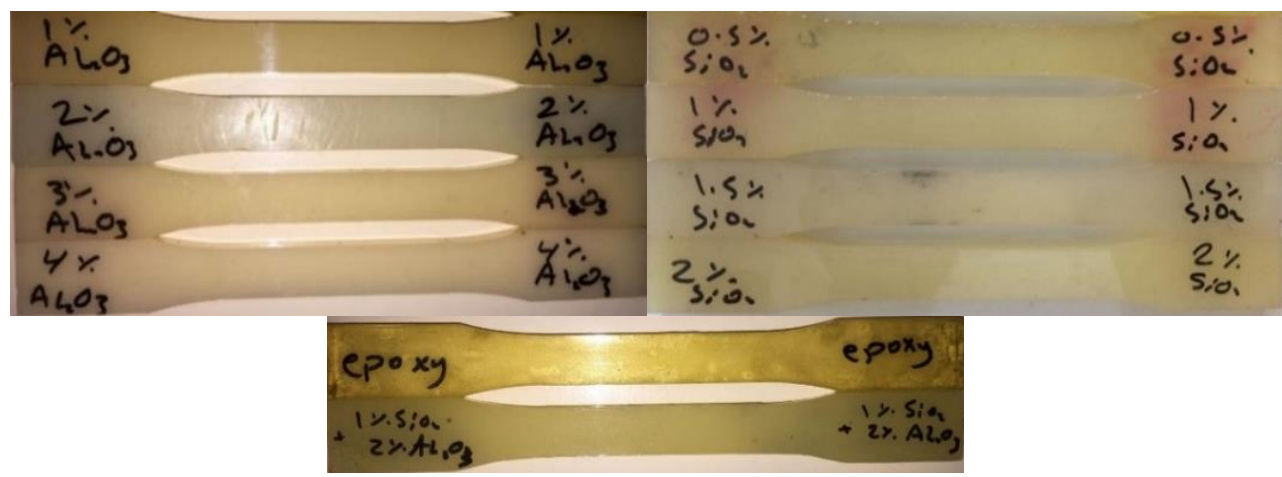

Fig.5. Tensile test specimens 


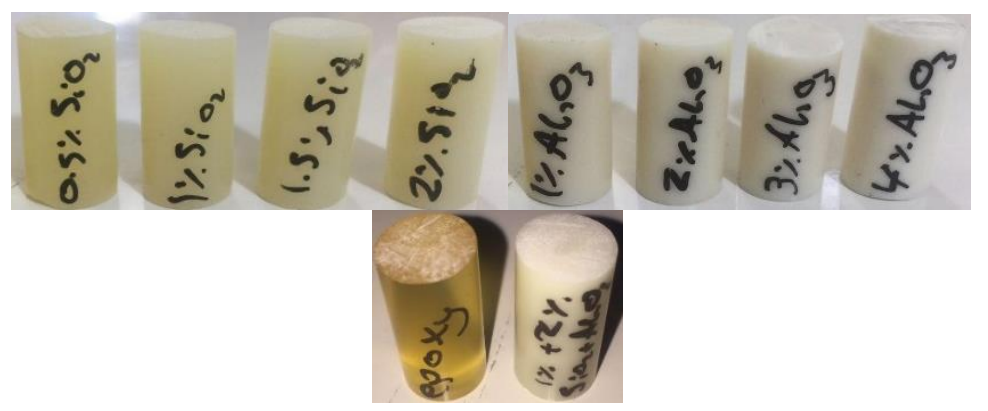

Fig.6. Compression test specimens

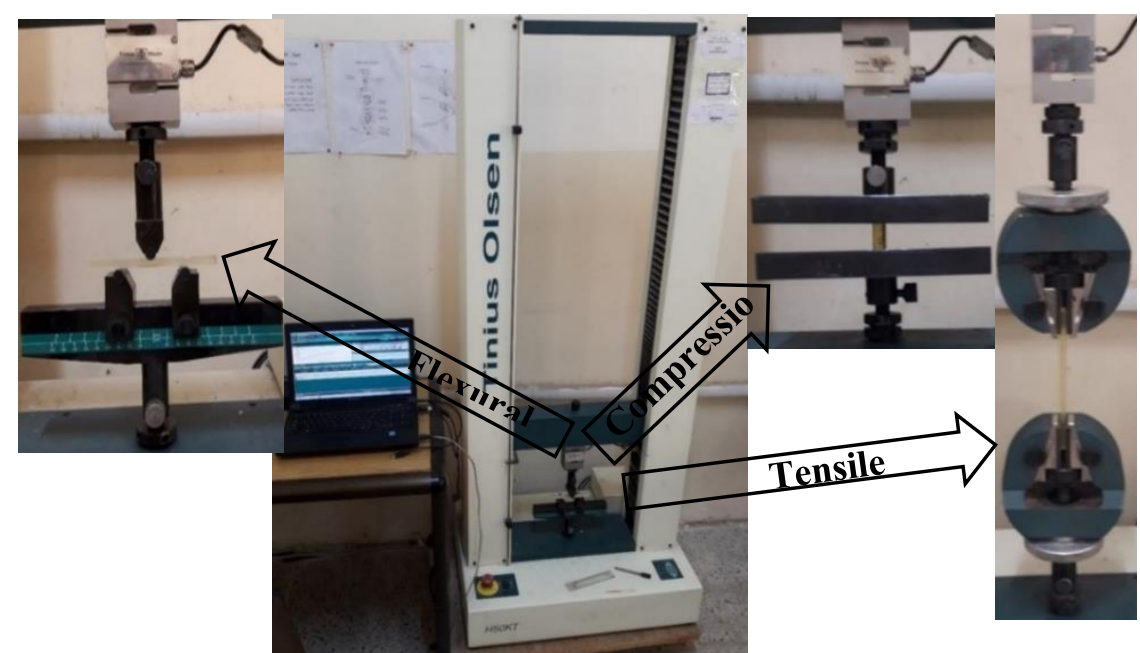

Fig.7. Tinius Olsen H50KT tensile testing machine and samples

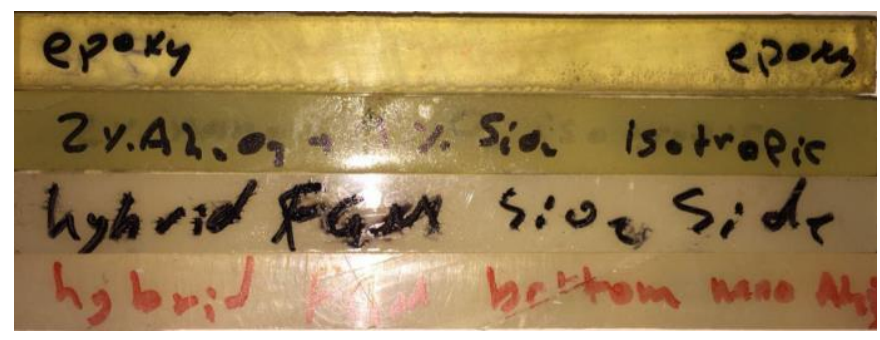

Fig.8. Flexural test specimens

Table 5. Theoretical and experimental densities of neat epoxy, homogeneous nanocomposites, functionally graded materials, and the matching void content

\begin{tabular}{|l|l|l|l|}
\hline Composite & $\begin{array}{l}\text { Theoretical } \\
\text { density }\left(\mathbf{g} / \mathbf{c m}^{3}\right)\end{array}$ & $\begin{array}{l}\text { Experimental } \\
\text { density }\left(\mathbf{g} / \mathbf{c m}^{3}\right)\end{array}$ & $\begin{array}{l}\text { Void content } \\
(\%)\end{array}$ \\
\hline Epoxy & 1.15 & 1.145 & 0.436 \\
\hline $1 \% \mathrm{SiO}_{2}$ & 1.163 & 1.149 & 1.261 \\
\hline $1.5 \% \mathrm{SiO}_{2}$ & 1.170 & 1.151 & 1.672 \\
\hline $2 \% \mathrm{Al}_{2} \mathrm{O}_{3}$ & 1.191 & 1.168 & 1.969 \\
\hline $3 \% \mathrm{Al}_{2} \mathrm{O}_{3}$ & 1.211 & 1.187 & 2.064 \\
\hline $1 \% \mathrm{SiO}_{2}+2 \% \mathrm{Al}_{2} \mathrm{O}_{3}$ & 1.177 & 1.148 & 2.526 \\
\hline $\mathrm{FGM}\left(1 \% \mathrm{SiO}_{2}+2 \% \mathrm{Al}_{2} \mathrm{O}_{3}\right)$ & 1.177 & 1.139 & 3.336 \\
\hline
\end{tabular}




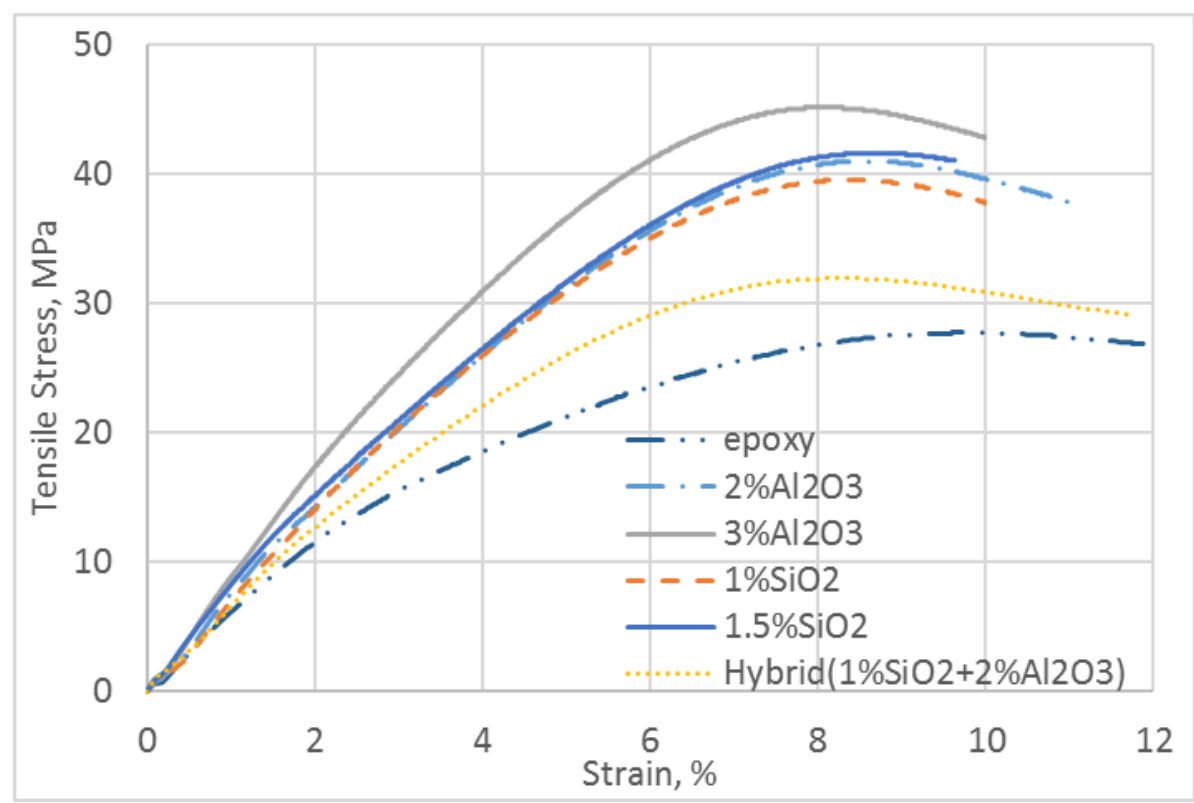

Fig.9. Stress-strain curves behaviour of the epoxy with different nanoparticles

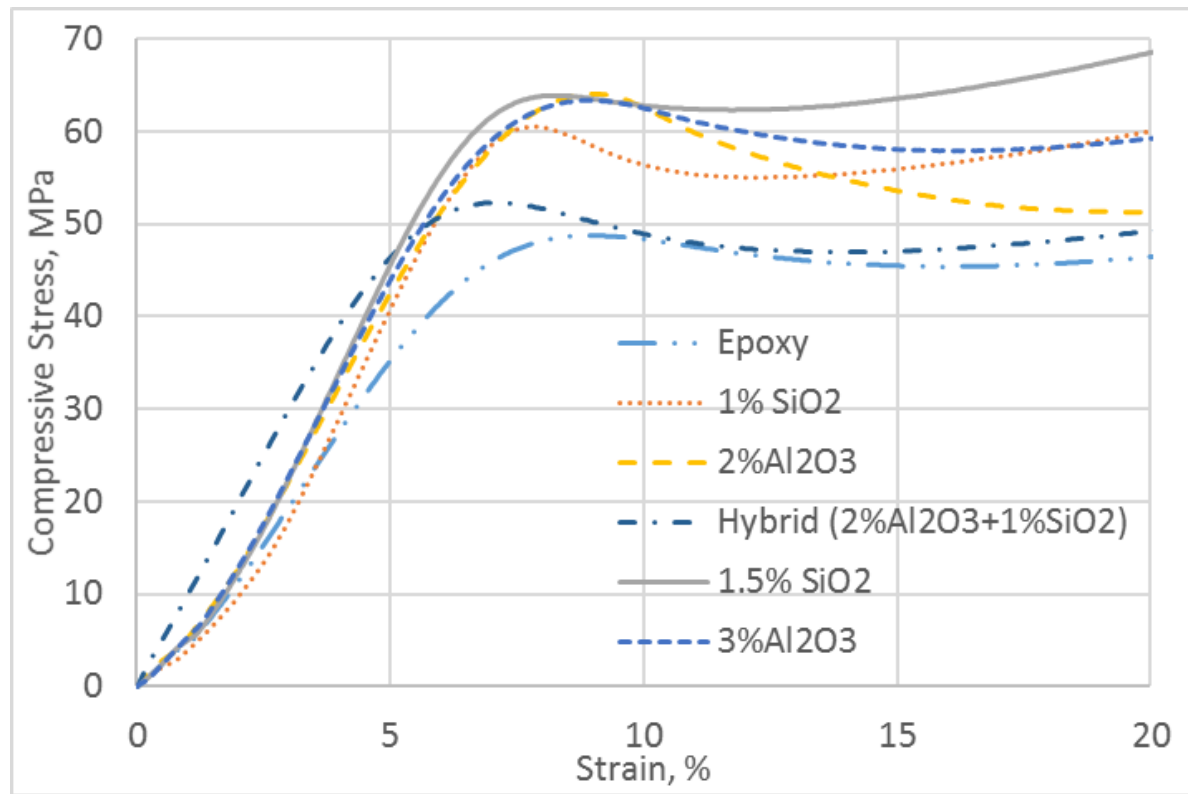

Fig.10. Stress-strain curves of the compressive stress behaviour of the nanocomposites of epoxy 


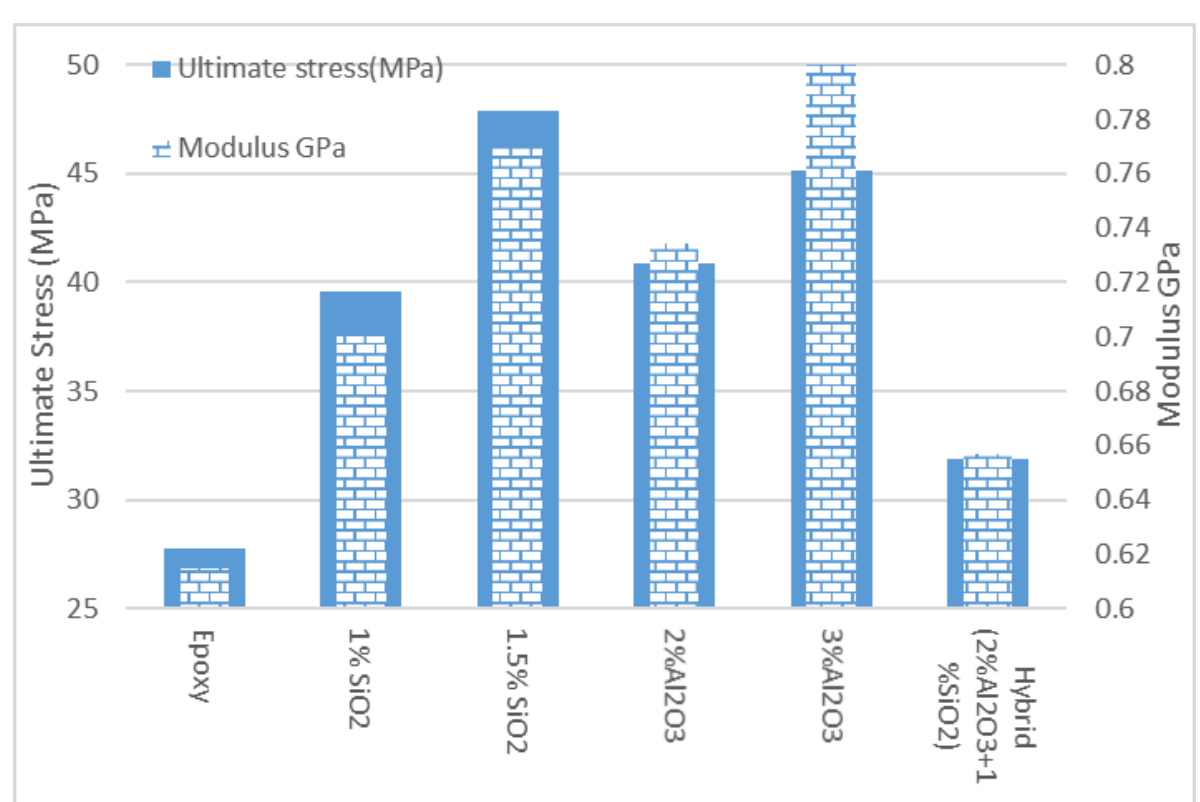

Fig.11. Nanoparticles influence upon the modulus of elasticity and the ultimate tensile strength

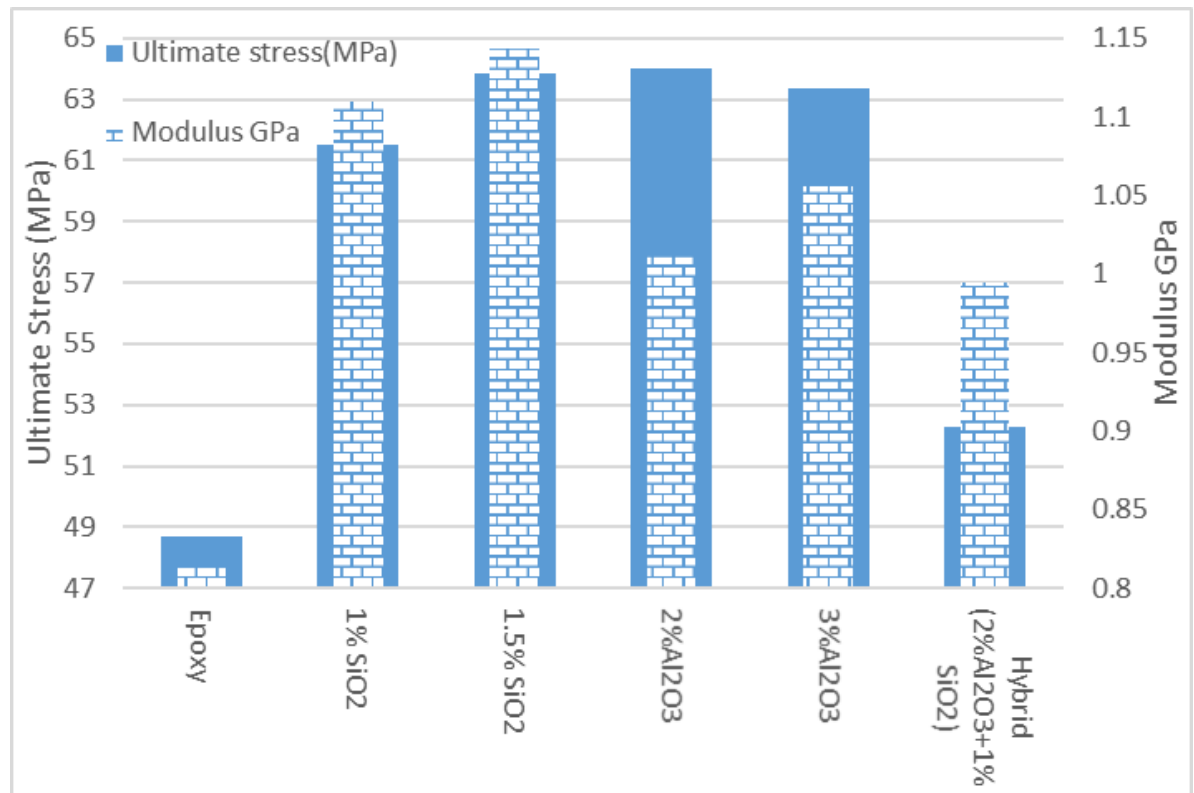

Fig. 12. Influence of the nanoparticles (Vf\%) of silica and alumina upon the ultimate compression stress and modulus of elasticity 


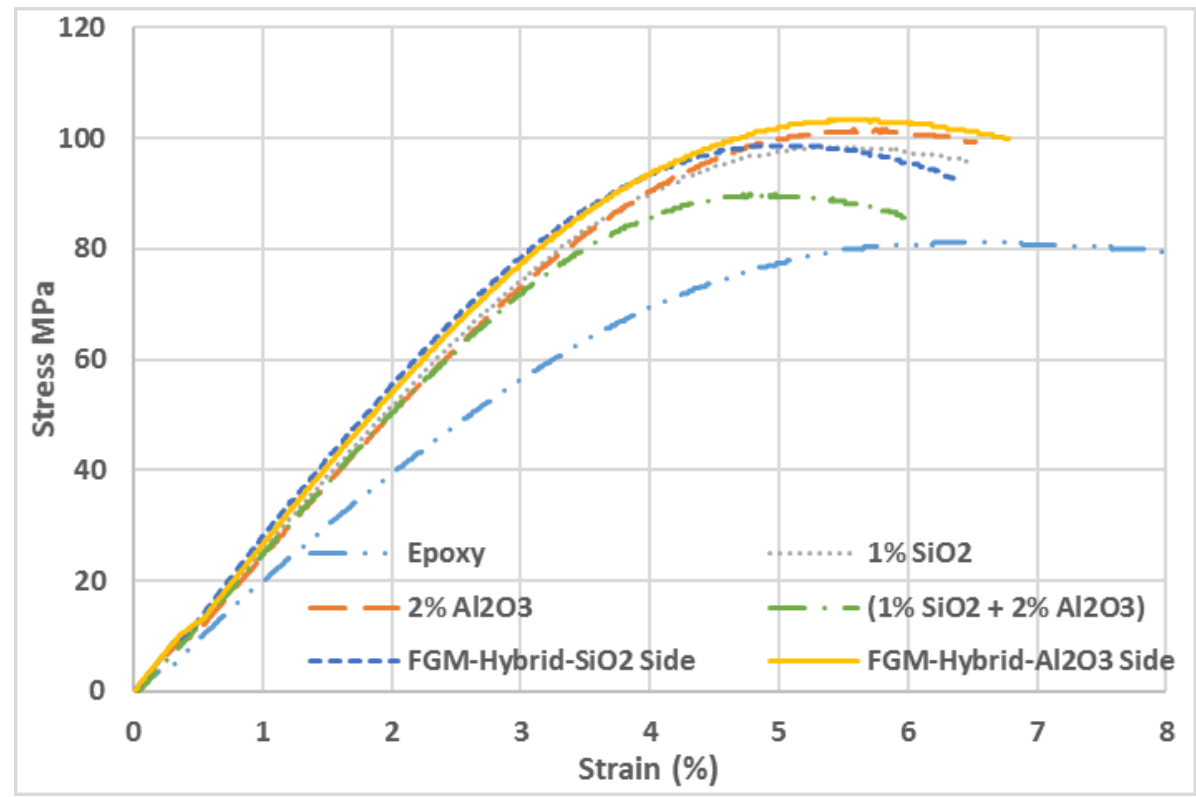

Fig 13. Stress-strain curves of the flexural behaviour for the FGPNC specimens

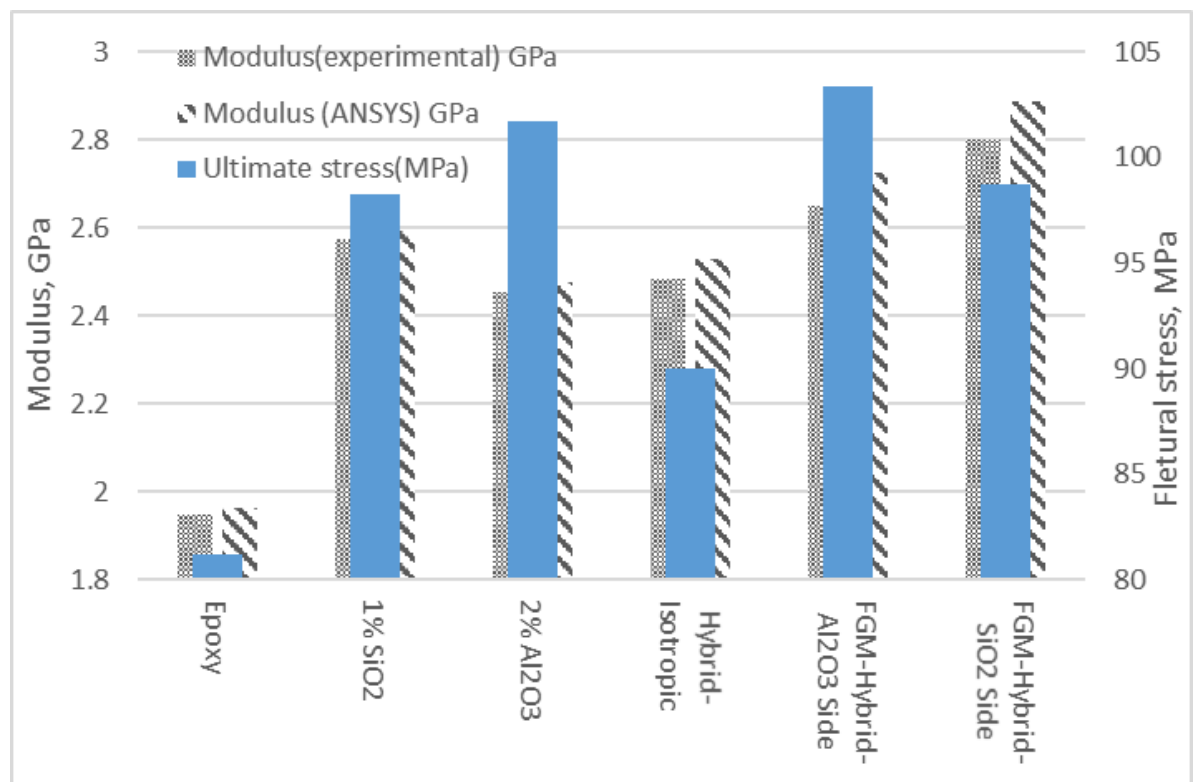

Fig.14. The flexural strength and the modulus of elasticity for the epoxy, isotropic and functionally graded materials

\section{REFERENCES}

Abbas A., and Raheem Z., "Hardness and Impact Strength of Functionally Graded Nanocomposites, "International Bimonthly, Vol. 9, No. 52, pp. 16683-16688, 2019.

Abbas A., and Raheem Z., "Flexural Properties of Functionally Graded Nanocomposites Address for Correspondence, "Indian Journal of Natural Sciences, Vol. 9, No. 52, 2019.

Ahmed F., Ammar Al-Kawaz, and Ahmed E., "Numerical and experimental investigation of functionally graded rubber-nano-composite core for sandwich structure," International Journal of Civil Engineering and Technology (IJCIET), Vol. 9, No. 13, pp. 199-206, 2018. 
Akant K. S., and Sanjay Y., "Investigations on mechanical peculiarity of Nano Titanium Oxide filled vinyl ester based Functionally Graded Materials," ITSEC International Journal of Engineering Sciences, Vol. 1, No. 1, pp. 12-15, 2020.

ASTM D638 Annual Book of ASTM Standards, American Society of Testing and Materials, West Conshohocken, 2015.

ASTM D695 Annual Book of ASTM Standards, American Society of Testing and Materials, West Conshohocken, 2015.

ASTM D790 West Conshohocken, PA: ASTM International, 2015.

Bhattacharya M., "Polymer Nanocomposites-A Comparison between Carbon Nanotubes, Graphene, and Clay as Nanofillers," Materials, Vol. 9, No. 4, pp. 262-297, 2016.

Ferdinand P., Beer, E., and Russell Johnston, "Mechanics of Materials," McGraw-Hill Education, New York, pp. 58, 2015.

Franco D., "Study and characterization of thermo-mechanical properties of fiber-reinforced and nano-structured composites based on engineering and high performance polymeric matrices for high temperature applications," $\mathrm{PhD}$ thesis, Department of Civil and Environmental Engineering, University of Florence, 2017.

Gangil B., Kukshal V., Sharma A., et al., "Development of hybrid fiber reinforced functionally graded polymer composites for mechanical and wear analysis," Proceedings of The 3rd International Conference on Automotive Innovation Green Energy Vehicle, 2019.

İrez A. B., and Bayraktar E., "Design of Epoxy Modified Recycled Rubber-Based Composites: Effects of Different Contents of Nano-Silica, Alumina and Graphene Nanoplatelets Modification on the Toughening Behavior," Gazi University Journal of Science, Vol. 33, No. 1, pp. 188-99, 2020.

Jeevanandam J., Barhoum A., Chan Y. S., et al. "Review on nanoparticles and nanostructured materials: history, sources, toxicity and regulations," Beilstein Journal of Nanotechnology, Vol. 9, pp. 1050-1074, 2018.

Li T., Xue J., Luo W., et al., "Effects of Power Ultrasound on Precipitation Process of Sodium Silicate Solutions," EPD Congress, pp. 109-126, 2015.

Mehditabar A., Rahimi G. H., and Vahdat S. E., "Mechanical Properties of Al 25 wt.\% Cu Functionally Graded Material," Science and Engineering of Composite Materials, Vol. 26, No. 1, pp. 327-337, 2019.

Mishra S. K., Shukla D. K., and Patel R. K., "Effect of particle morphology on flexural properties of functionally graded epoxy-alumina polymer nanocomposite," Materials Research Express, Vol. 6, No. 12, 2020. 
Noor Abdulateef G., Mohammed N. A./ and Dawood E. S. "Preparing of Alumina from Aluminum Waste," International Journal of Innovative Science and Research Technology, Vol. 4, No. 3, 2019.

Parihar R. S., Gangi Setti S., and Sahu, R. K., "Preliminary investigation on development of functionally graded cemented tungsten carbide with solid lubricant via ball milling and spark plasma sintering," Journal of Composite Materials, Vol. 52, No. 10, pp. 1363-1377, 2017.

Saleh B., Jiang J., Fathi, R., et al., "30 Years of functionally graded materials: An overview of manufacturing methods, Applications and Future Challenges," Composites Part B: Engineering, Vol. 201, 2020.

Shareef M. M. S., Al-Khazraji A. N., and Amin, S. A. "Flexural Properties of Functionally Graded Silica Nanoparticles," IOP Conference Series: Materials Science and Engineering, Vol. 1094, No. 1, 2021.

Shareef M. M. S., Al-Khazraji A. N., and Amin, S. A "Flexural Properties of Functionally Graded Polymer Alumina Nanoparticles," Engineering and Technology Journal, Vol. 39, No. 5A, pp. 821-835, 2021.

Singh A. K., and Vashishtha S. "Mechanical and Tribological Peculiarity of Nano-TiO2 Augmented, Polyester-Based Homogeneous Nanocomposites and Their Functionally Graded Materials," Advances in Polymer Technology, Vol. 37, No. 3, pp. 679-696, 2016.

Uygunoglu T., Gunes I., and Brostow W., "Physical and Mechanical Properties of Polymer Composites with High Content of Wastes Including Boron," Materials Research, Vol. 18, No. 6, pp. 1188-1196, 2015. 